ploid elements a homogeneous population as to their deoxyribonucleic acid content.

This work was aided by a grant of the Belgium F.N.R.S,

\section{R. LAquerRitire}

Belgian Centre of Growth and Differentiation, Department of Human and Comparative Anatomy, University of Ghent.

1 Gerzeli, G., Arch. Biol., 68, 1 (1957).

Laquerriere, R., C.R. Soc. Biol. (in the press).

${ }^{3}$ Yison, L., Acta Anat., 10, 333 (1950).

\section{3,4-Dihydroxyphenylalanine and 5-Hydroxy- tryptophan as Reserpine Antagonists}

THE depletion by reserpine of storage in the body of 5-hydroxytryptamine ('Serotonin') and of the catechol amines is now well established ${ }^{1-3}$. In reserpinized animals the peripheral part of the adrenergic system does not function owing to lack of the transmitter ${ }^{2}$. This is presumably true also of the central part of the adrenergic system. However, it remains to be proved to what extent the central action of reserpine may be attributed to changes in brain catechol amines and/or 5-hydroxytryptamine.

If lack of amines were responsible for the central action of reserpine, administration of the amines in question should counteract these effects, provided that the amines were capable of entering the brain. However, 5-hydroxytryptamine has been shown not to penetrate the blood-brain barrier readily, and this may be true also of the catechol amines. This difficulty may be overcome by administering the amino-acid precursors of the amines. Thus injection of 5-hydroxytryptophan is followed by an increase in the level of 5-hydroxytryptamine in brain as well as by central excitation ${ }^{4}$. Preliminary experiments in this laboratory have shown that in this respect 3,4-dihydroxyphenylalanine, which is the precursor of the catechol amines (dopamine, noradrenaline, and adrenaline), behaves similarly.

Experiments were performed on mice (males weighing about $10 \mathrm{gm}$.), which received an intra. peritoneal injection of reserpine $(20-40 \mathrm{mgm}$. per kgm.). After about $16 \mathrm{hr}$., when the animals were markedly tranquillized and showed complete ptosis of the eyelid, 5-hydroxytryptophan, 3,4-dihy. droxyphenylalanine, or a nixture of both amino-acids (in the DL-form throughout) were injected intraperitoneally. In doses up to $1,000 \mathrm{mgm}$. per $\mathrm{kgm}$. 5 -hydroxytryptophan was unable to antagonize the tranquillizing action of reserpine: ptosis persisted. On the other hand, the response to 3,4-dihydroxyphenylalanine was dramatic. Within 15-30 min. after a dose of 500-1,000 mgm. por kgm. the animals resumed almost normal behaviour or even showed signs of overactivity, and ptosis disappeared. The effect did not last much longer than an hour, after which the animals gradually returned to the same condition as before the injection of 3,4-dihydroxyphenylalanine. Although 5-hydroxytryptophan given alone had no effect, a mixture of equal amounts of 5-hydroxytryptophan and 3,4-dihydroxyphenylalanine 250-500 mgm. per $\mathrm{kgm}$.) produced a more complete and longer-lasting counteraction of the reserpine effect than did the same dose of 3,4-dihydroxyphenylalanine alone.
A dramatic effect of 3,4-dihydroxyphenylalanine (200 .mgm. per kgm. intravenously) was observed also in rabbits which had received reserpine in a dose of $5 \mathrm{mgm}$. per $\mathrm{kgm}$. intravenously $4 \mathrm{hr}$. earlier. Within 10-15 min. after the injection of 3,4-dihydroxyphenylalanine the tranquillization as well as ptosis and meiosis caused by reserpine had disappeared completely. If the animal had received iproniazid (100 mgm. per kgm. intravenously) about $2 \mathrm{hr}$. before the 3,4-dihydroxyphenylalanine, the dose of the latter required to antagonize the effect of reserpine was markedly reduced. This supports the assumption that the effect of 3,4-dihydroxyphenylalanine was due to an amine formed from it. (The iproniazid, when administered about two hours after the reserpine as in these experiments, did not per se counteract the tranquillizing effect of reserpine.) In normal rabbits 3,4-dihydroxyphenylalanine caused central stimulation, which was likewise markedly potentiated by iproniazid pretreatment.

A full account of these experiments will be publisherl elsewhere.

Arvid Carlsson

Mareit Lindevist Tor Magnusson

Department of Pharmacology,

University of Lund, Lund.

June 19. Shore, P. A., Pletscher, A., Tomich, E. G., Carlsson, A., Kuntz-
man, R., and Brodie, B. B., Ann. N.Y. Acaul. Sci., 66, 609 (1957), 2 Carlsson, A., Rosengren, E., Bertler, $\mathbf{A} .$, and Nilsson, J., Internat
Symp. on Psychotropic Drugs, May 9 -11, 1957 (in the press).

${ }^{3}$ Shore, P. A., and Brodie, B. B., Internat. Symp. on Psychotropic Drugs, May 9-11, 1957 (in the press).

"Udenfriend, S., Weissbach, H., and Bogdanski, D. F., Ann. N.Y. Acad. Sci., 68, 802 (1957).

\section{Antihypertensive Activity of Hexahydro- l-Azep:nepropionamidoxime}

HEXAHYDRO-1-AZEPINEPROPIONAMIDOXIME dihydrochloride (I), designated as $S U-4029$, has been studied for its effect on the cardiovascular system of the dog.<smiles>NC(CN1CCCCCC1)=NO</smiles>

A single intravenous dose of $30 \mathrm{mgm} . / \mathrm{kgma}$. of this compound lowered the arterial pressure of neurogenic and renal hypertensive dogs while not notably affecting the blood pressure of normotensive dogs. However, in normotensive animals $30 \mathrm{mgm}$. $/ \mathrm{kgm}$. of $S U-4029$ given intravenously eliminated the severe hypertension elicited by high doses of amphetamine and ephedrine and also markedly antagonized carotid occlusion reflex pressor responses. These antihypertensive effects were slow in onset and lasted for approximately two to six weeks following single injection. $S U-4029$ was orally active and had a cumulative action when given in small daily doses.

'To prepare the compound, hexahydroazepine was cyanoethylated and gave hexahydro-l-azepinepropionitrile $^{1}$, b.p. $121-123^{\circ} / 14 \mathrm{~mm}$.; $n_{D}^{30} 1.4710$ (found: C, 70.82; H, $10.52 ; \mathrm{N}, 18.53$ per cent. $\mathrm{C}_{9} \mathrm{H}_{18} \mathrm{~N}_{2}$ requires : $\mathrm{C}, 71 \cdot 1 \mathrm{l} ; \mathrm{H}, 10.61 ; \mathrm{N}, 18.43$ per cent). Treatment of this nitrile with hydroxyl- 